\title{
Chronic Antidepressant Treatment Increases Neurogenesis in Adult Rat Hippocampus
}

\author{
Jessica E. Malberg, Amelia J. Eisch, Eric J. Nestler, and Ronald S. Duman \\ Laboratory of Molecular Psychiatry, Departments of Psychiatry and Pharmacology, Yale University School of Medicine, \\ Connecticut Mental Health Center, New Haven, Connecticut 06508
}

\begin{abstract}
Recent studies suggest that stress-induced atrophy and loss of hippocampal neurons may contribute to the pathophysiology of depression. The aim of this study was to investigate the effect of antidepressants on hippocampal neurogenesis in the adult rat, using the thymidine analog bromodeoxyuridine (BrdU) as a marker for dividing cells. Our studies demonstrate that chronic antidepressant treatment significantly increases the number of BrdU-labeled cells in the dentate gyrus and hilus of the hippocampus. Administration of several different classes of antidepressant, but not non-antidepressant, agents was found to increase BrdU-labeled cell number, indicating that this is a common and selective action of antidepressants. In addition, upregulation of the number of BrdU-labeled cells is observed
\end{abstract}

after chronic, but not acute, treatment, consistent with the time course for the therapeutic action of antidepressants. Additional studies demonstrated that antidepressant treatment increases the proliferation of hippocampal cells and that these new cells mature and become neurons, as determined by triple labeling for BrdU and neuronal- or glial-specific markers. These findings raise the possibility that increased cell proliferation and increased neuronal number may be a mechanism by which antidepressant treatment overcomes the stress-induced atrophy and loss of hippocampal neurons and may contribute to the therapeutic actions of antidepressant treatment.

Key words: proliferation; granule cell; fluoxetine; tranylcypromine; reboxetine; depression
Depression is a devastating illness that is estimated to affect 12$17 \%$ of the population at some point during the lifetime of an individual (Kessler et al., 1994). Antidepressants are commonly prescribed for depression and other affective disorders, although the molecular and cellular mechanisms by which these agents exert their therapeutic effects are not well understood. Preclinical and clinical research has focused on the interactions between stress and depression and their effects on the hippocampus, among other brain regions (Duman et al., 1999; McEwen, 1999). For example, the hippocampus has been shown to undergo morphological changes in response to stress, including atrophy and loss of CA3 pyramidal neurons after exposure to physical or psychosocial stress (Watanabe et al., 1992c; Stein-Behrens et al., 1994; Margarinos et al., 1996; McEwen, 1999). In addition, brain-imaging studies demonstrate that hippocampal volume is decreased in patients with stress-related psychiatric illnesses, including depression and posttraumatic stress disorder (Sapolsky, 1996; Sheline et al., 1996).

The hippocampus is one of only a few brain regions where production of neurons occurs throughout the lifetime of animals, including humans (Eriksson et al., 1998). Hippocampal neurogenesis can be influenced by several environmental factors and stimuli (Kuhn et al., 1996; Kempermann et al., 1997; Gould et al., 1999a; van Praag et al., 1999b). Importantly, it has been shown that stressful experiences, including both physical and psychosocial stress, suppress the formation of hippocampal granule cells in a number of mammalian species (Gould et al., 1997, 1998; Tanapat et al., 1998). Decreased cell proliferation has also been reported in response to both acute and chronic stress paradigms (Fuchs et al., 1997). It is conceivable that the stress-induced downregulation of granule cell genesis, as well as atrophy and death of CA3 pyramidal neurons, contributes to the reduction in hippocampal volume that is clinically observed (Sapolsky, 1996; Sheline et al., 1996; Duman et al., 1999).

Received July 17, 2000; revised Sept. 13, 2000; accepted Sept. 22, 2000.

This work is supported by United States Public Health Service Grants MH45481, MH53199, and 2 PO1 MH25642, and by a Veterans Administration (VA) National Center Grant for post-traumatic stress disorder, VA Medical Center.

Correspondence should be addressed to Dr. Ronald S. Duman, 34 Park Street, New Haven, CT 06508. E-mail: ronald.duman@yale.edu.

Copyright (C) 2000 Society for Neuroscience $0270-6474 / 00 / 209104-07 \$ 15.00 / 0$
The possibility that antidepressant treatment could oppose or reverse the actions of stress on the morphology and proliferation of hippocampal neurons is suggested by studies demonstrating that antidepressants upregulate the expression of brain-derived neurotrophic factor (BDNF) in the hippocampus (Nibuya et al., 1995). BDNF has been shown to promote the differentiation and survival of neurons during development and in adult brain, as well as in cultured cells (Memberg and Hall, 1995; Palmer et al., 1997; Takahashi et al., 1998). In addition, chronic antidepressant treatment completely blocks the stress-induced downregulation of BDNF expression in the hippocampus, demonstrating that antidepressant treatment can oppose the dystrophic actions of stress (Nibuya et al., 1995).

Given the association between depression, stress, and hippocampal neurogenesis, the current series of studies was performed to determine whether antidepressant administration influences hippocampal neurogenesis in the adult rat. After administering different classes of antidepressant drugs or electroconvulsive seizure (ECS), we administered bromodeoxyuridine (BrdU), a thymidine analog that labels dividing cells in S-phase (Takahashi et al., 1992). The effects of antidepressant treatment on proliferation, differentiation, and survival of cells in the dentate gyrus and hilus of the hippocampus were determined using several treatment paradigms.

\section{MATERIALS AND METHODS}

Antidepressant treatment. Adult male Sprague Dawley rats (Harlan Sprague Dawley, Indianapolis, IN) weighing 250-300 gm were used for all experiments. All animal treatments and maintenance of the rat colony were in accordance with National Institutes of Health laboratory care standards. Animals were group-housed ( $12 \mathrm{hr}$ light/dark cycle) with ad libitum access to food and water. After at least $3 \mathrm{~d}$ of habituation to the rat colony, rats were administered either an antidepressant or vehicle. ECS was administered via earclip electrodes $(50 \mathrm{~mA}, 0.3 \mathrm{sec})$ once daily for $10 \mathrm{~d}$. Earclips were applied to control animals, but no electrical current was administered. Drugs and their vehicles were administered intraperitoneally according to standard regimens (Nibuya et al., 1995, 1996): tranylcypromine, $7.5 \mathrm{mg} / \mathrm{kg}$ for the first $7 \mathrm{~d}$ and then $10 \mathrm{mg} / \mathrm{kg}$ for $14 \mathrm{~d}$; reboxetine, 20 $\mathrm{mg} / \mathrm{kg}, 2 \times$ per day for $21 \mathrm{~d}$; fluoxetine, $5 \mathrm{mg} / \mathrm{kg}$ for $1,5,14$, or $28 \mathrm{~d}$; haloperidol, $1 \mathrm{mg} / \mathrm{kg}$ for the first $7 \mathrm{~d}$ and then $2 \mathrm{mg} / \mathrm{kg}$ for $7 \mathrm{~d}$; vehicles, 1 $\mathrm{ml} / \mathrm{kg}$ saline for tranylcypromine and reboxetine, $1 \mathrm{ml} / \mathrm{kg}$ distilled water for fluoxetine, and $1 \mathrm{ml} / \mathrm{kg}$ DMSO for haloperidol ( $n=8$ for each group).

BrdU labeling. For analysis of BrdU-positive cells, rats were administered $\mathrm{BrdU}(4 \times 75 \mathrm{mg} / \mathrm{kg}$ every $2 \mathrm{hr}$; Sigma, St. Louis, MO) $4 \mathrm{~d}$ after the 
A. Proliferation and differentiation paragdigm

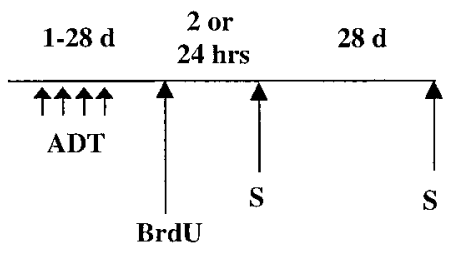

B. Survival paradigm

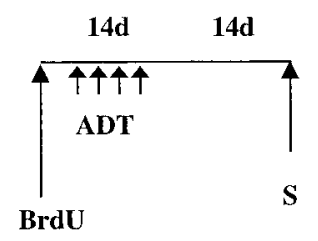

Figure 1. Experimental paradigms. A, Proliferation and differentiation paradigms. Animals were administered antidepressants for 1-28 d. Four days after the last antidepressant treatment, animals were given BrdU and killed $(S) 24 \mathrm{hr}$ after BrdU administration. In one experiment designed to measure cell proliferation, animals were killed $2 \mathrm{hr}$ after BrdU injection. To determine cell differentiation or phenotype, rats were killed $28 \mathrm{~d}$ after BrdU injection. $B$, Survival paradigm. To examine the influence of antidepressant treatment on the survival of BrdU-labeled cells, BrdU was given to drug-naïve animals before initiating antidepressant treatment (14 d). Rats were then killed $28 \mathrm{~d}$ after BrdU injection (14 d after the last antidepressant treatment).

last antidepressant or haloperidol treatment (Fig. 1A). The $4 \mathrm{~d}$ time point was chosen because a similar paradigm has been used in a previous study of chemical-induced seizures on hippocampal neurogenesis (Parent et al. 1997). Twenty-four hours after the last BrdU injection, rats were killed and transcardially perfused $(0.1 \mathrm{M}$ cold PBS for $5 \mathrm{~min}$ followed by $4 \%$ cold paraformaldehyde for $17 \mathrm{~min}$ ). For determination of cell phenotype, ECSor fluoxetine (14 d)-treated rats were allowed to survive $28 \mathrm{~d}$ after the last BrdU injection (Fig. 1 $A$ ). To investigate the effect of antidepressant treatment specifically on cell proliferation, ECS- or fluoxetine (14 d)treated rats were given one injection of $\operatorname{BrdU}(75 \mathrm{mg} / \mathrm{kg})$ and perf used 2 hr later (Fig. $1 A$ ).

To determine the effects of antidepressants on cell survival, BrdU was administered before chronic administration of fluoxetine (Fig. 1B). BrdU $(4 \times 75 \mathrm{mg} / \mathrm{kg}$ every $2 \mathrm{hr})$ was administered to drug-naive rats, and $24 \mathrm{hr}$ after the last BrdU injection, rats were started on a chronic regimen of fluoxetine $(5 \mathrm{mg} / \mathrm{kg}$ for $14 \mathrm{~d})$. Twenty-eight days after the last BrdU injection ( $\sim 14 \mathrm{~d}$ after ECT or fluoxetine treatment, respectively) rats were perfused, and brains were processed for immunohistochemistry.

After perfusion, all brains were post-fixed overnight in paraformaldehyde (with shaking) at $4^{\circ} \mathrm{C}$ and stored at $4^{\circ} \mathrm{C}$ in $30 \%$ sucrose. Serial sections of the brains were cut ( $35 \mu \mathrm{m}$ sections) through the entire hippocampus (plates 26-40; Paxinos and Watson, 1986) on a freezing microtome, and sections were stored in $\mathrm{PBS} / \mathrm{NaN}_{3}$.

Immunohistochemistry. Free-floating sections were used in the determination of BrdU labeling. DNA denaturation was conducted by incubation for $2 \mathrm{hr}$ in $50 \%$ formamide $/ 2 \times \mathrm{SSC}$ at $65^{\circ} \mathrm{C}$, followed by several PBS rinses. Sections were then incubated for $30 \mathrm{~min}$ in $2 \mathrm{~N} \mathrm{HCl}$ and then $10 \mathrm{~min}$ in boric acid. After washing in PBS, sections were incubated for $30 \mathrm{~min}$ in $3 \%$ $\mathrm{H}_{2} \mathrm{O}_{2}$ to eliminate endogenous peroxidases. After blocking with $3 \%$ normal horse serum (NHS) in $0.01 \%$ Triton X-100, cells were incubated with anti-mouse BrdU (1:1000; Boehringer-Mannheim, Indianapolis, IN) overnight at $4^{\circ} \mathrm{C}$. Sections were then incubated for $1 \mathrm{hr}$ with secondary antibody (biotinylated horse anti-mouse; Vector Laboratories, Burlingame, CA) followed by amplification with an avidin-biotin complex (Vector Laboratories), and cells were visualized with DAB (Vector Laboratories).

For double and triple labeling, sections were slide-mounted and boiled in citric acid, $\mathrm{pH} 6.0$, for $10 \mathrm{~min}$ followed by PBS rinses and then treatment with $0.01 \%$ trypsin in Tris $/ \mathrm{CaCl}_{2}$ for $10 \mathrm{~min}$. Brain sections were incubated for 30 min with $2 \mathrm{~N} \mathrm{HCl}$ and blocked with $10 \%$ NHS (Vector Laboratories). Sections were then incubated for $3 \mathrm{~d}$ at $4^{\circ} \mathrm{C}$ with anti-rat $\mathrm{BrdU}(1: 200$; Accurate; Harlan Olac, Bicester, UK) and one of the following: anti-mouse neuronal nuclei (NeuN) (1:50; Chemicon, Temecula, CA) or anti-mouse glial fibrillary acidic protein (GFAP) (1:100; ICN Biochemicals, Costa Mesa, CA). For triple labeling, BrdU, NeuN, and anti-rabbit GFAP (1:50; ICN Biochemicals) were used. After washes, secondary antibodies $\mathrm{Cy} 2$ (1:200), Cy3 (1:500), and Cy5 (1:500) (Jackson ImmunoResearch, West Grove, PA) were applied for $1 \mathrm{hr}$ and visualized with confocal z-plane sectioning (Zeiss LSM 510).

Quantitation of BrdU labeling. A modified unbiased stereology protocol was used that has been reported to successfully quantitate BrdU labeling
(West et al., 1991; Gould et al., 1999a; Eisch et al., 2000). Two major considerations in stereological analyses are that no BrdU-labeled cells be counted twice and that the area counted be consistent in each section.

Every sixth section throughout the hippocampus was processed for BrdU immunohistochemistry. Using this spacing ensures that the same neuron will not be counted in two sections. All BrdU-labeled cells in the dentate gyrus (granule cell layer) and hilus were counted in each section by an experimenter blinded to the study code. To distinguish single cells within clusters, all counts were performed at $400 \times$ and $1000 \times$ under a light microscope (Olympus BX-60), omitting cells in the outermost focal plane. A cell was counted as being in the subgranular zone (SGZ) of the dentate gyrus if it was touching or in the SGZ. Cells that were located more than two cells away from the SGZ were classified as hilar. The total number of BrdU-labeled cells per section was determined and multiplied by 6 to obtain the total number of cells per dentate gyrus. ANOVA and post hoc Tukey tests were performed on these totals with Bonferroni correction for multiple comparisons.

To control for a nonspecific effect of antidepressant treatment on BrdU uptake and labeling and to determine whether the effects are specific to hippocampal neurogenesis, striatal sections were processed for BrdU labeling in the subventricular zone of the lateral ventricle. BrdU-positive cells on the lateral side of the lateral ventricle were counted $(1000 \times$ magnification; 10.0-9.0 $\mu \mathrm{m}$ intra-aural; Paxinos and Watson, 1986). At least eight sections were examined per animal ( $n=5$ rats per group), and statistical analysis was performed on the average number of BrdU-positive cells per section.

For double labeling, slices were analyzed on a confocal microscope (Zeiss Axiovert LSM510). At least 50 BrdU-positive cells per animal were analyzed using Z-plane sectioning (1 $\mu \mathrm{m}$ steps $)$ to confirm the colocalization of both BrdU and the markers NeuN, neuron-specific enolase (NSE), or GFAP. Triple labeling was performed for further verification of cell phenotype.

\section{RESULTS}

\section{Chronic antidepressant treatment increases the number of BrdU-positive cells}

A modified stereology protocol was used to count the number of BrdU-positive cells throughout the SGZ and hilus (West et al., 1991; Gould et al., 1999a). The SGZ, the border between the granule cell layer and hilus, has been shown to contain the progenitor cells that divide and migrate into the granule cell layer where they mature into neurons or astrocytes (Cameron et al., 1993). The percentage of BrdU-positive cells in the hilus and SGZ was the same in control and antidepressant-treated groups, so the cell counts in the two regions were summed to give the total number of labeled cells per dentate gyrus used in the statistical analysis.

Analysis of the number of BrdU-labeled cells demonstrated that chronic antidepressant administration significantly increased the number of BrdU-positive cells in the dentate gyrus (Fig. 2) relative to control. Chronic administration of ECS increased the number of BrdU-labeled cells by $\sim 50 \%$, whereas the chemical antidepressants increased the BrdU labeling by $20-40 \%$ (Fig. 3). ECS is clinically the most effective treatment for refractory depression, and this increase in BrdU-positive cells is in agreement with a report by previous investigators (Madsen et al., 2000). The chemical antidepressants tested include a monoamine oxidase inhibitor (tranylcypromine), a serotonin-selective reuptake inhibitor (fluoxetine), and a norepinephrine-selective reuptake inhibitor (reboxetine).

Next, the time course for antidepressant regulation of BrdU labeling was examined. Administration of fluoxetine for 1 or $5 \mathrm{~d}$ did not significantly affect the number of BrdU-positive cells compared with control (Fig. 4). After 14 or $28 \mathrm{~d}$ of fluoxetine treatment, a significant increase in BrdU-positive cells was seen compared with vehicle-treated controls and 1 or $5 \mathrm{~d}$ of treatment. This indicates that chronic, but not acute, antidepressant treatment increases BrdU labeling in the hippocampus, which is consistent with the time course for the therapeutic action of antidepressants (Duman et al., 1997).

To determine whether upregulation of the number of BrdUlabeled cells is specific to antidepressants, the influence of a nonantidepressant psychotropic drug was examined. Chronic administration of a clinically relevant dose of haloperidol, an antipsychotic agent, did not significantly influence the number of BrdU-labeled cells in dentate gyrus (vehicle, $4117 \pm 259$; haloperidol, $3788 \pm 238$ BrdU-labeled cells; mean \pm SEM; $n=6$ per group). This indicates that the increase in BrdU-positive cells may be specific to antide- 

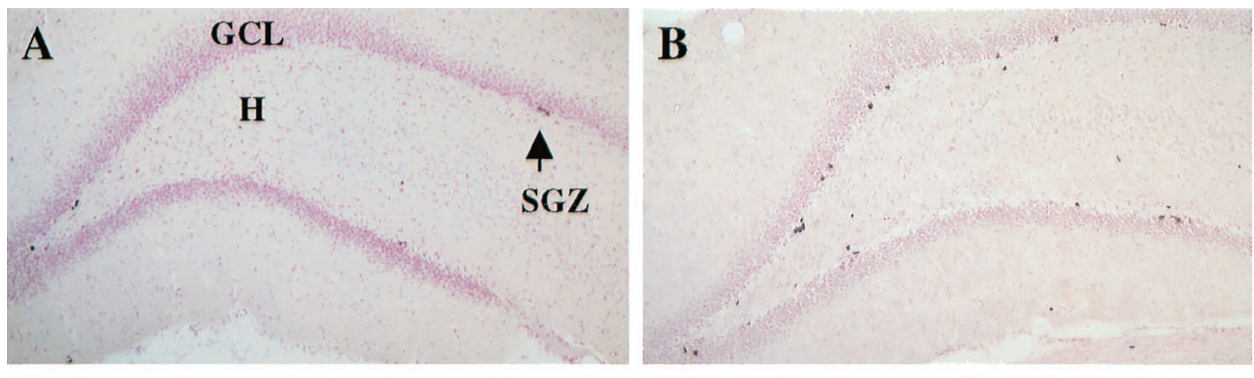

Figure 2. The number of BrdU-positive cells in the adult hippocampus is increased after chronic antidepressant treatment. Rats received injections of BrdU $4 \mathrm{~d}$ after the last ECS $(10 \mathrm{~d})$ or drug $(14-21 \mathrm{~d})$ treatment and were killed $24 \mathrm{hr}$ after the last BrdU injection. Shown are representative photomicrographs $(10 \times$ magnification) from vehicle $(A)$, tranylcypromine $(B)$, ECS $(C)$, or fluoxetine $(D)$. The majority of the BrdU-labeled cells are located in the subgranular zone ( $S G Z$, indicated by arrow in $A$ ) of the hippocampus, the region between the granule cell layer $(G C L)$ and hilus $(H)$.
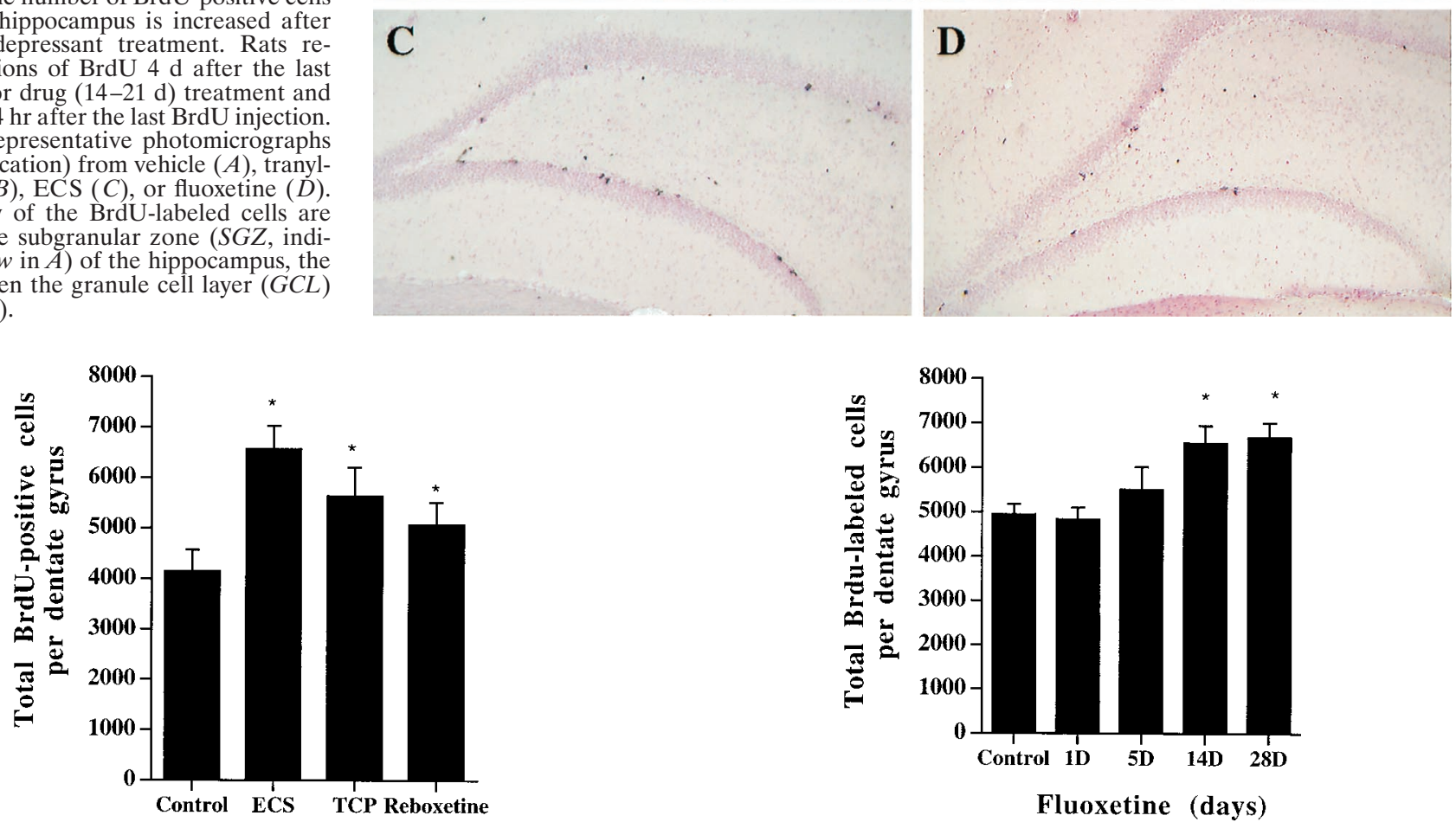

Figure 3. Chronic antidepressant treatment increases BrdU labeling in the adult hippocampus. Rats received BrdU injections $4 \mathrm{~d}$ after the last ECS or drug treatment, as described in Figure 2. The results are the mean \pm SEM number of BrdU-positive cells in hippocampus ( $n=8$ per group). ECS, Electroconvulsive shock; TCP, tranylcypromine. ${ }^{*} p<0.05$ significantly different from vehicle control $\left(F_{(3,28)}=7.05 ; p<0.05\right)$.

pressants. In addition, we have found that chronic administration of morphine decreases granule cell proliferation, an effect opposite to that of antidepressant treatment (Eisch et al., 2000).

\section{Chronic antidepressant treatment increases cell proliferation}

To specifically isolate the effect of antidepressant treatment on cell proliferation, rats were administered ECS $(10 \mathrm{~d})$ or fluoxetine $(14$ d), given a single injection of BrdU, and killed $2 \mathrm{hr}$ later. At this time point, both ECS and fluoxetine treatment significantly increased the number of BrdU-positive cells relative to the respective controls (vehicle, $3610 \pm 330$; fluoxetine, $4350 \pm 420$; ECS, $5780 \pm$ $720 ; F(2,18)=6.89 ; p<0.05)$. These results indicate that antidepressant treatment increases the proliferation of hippocampal cells.

In all of the animals killed at either 2 or $24 \mathrm{hr}$ after BrdU injection, the BrdU-positive cells in the hilus and dentate gyrus were found in clusters (Fig. $5 A-C$ ), with irregularly shaped nuclei and diffuse patterns of BrdU staining. This is representative of immature cells undergoing division (Kuhn et al., 1996; Parent et al., 1997). The number of cells per cluster was not affected by ECS or chemical antidepressant treatments. In addition, in all animals killed at $2 \mathrm{hr}$, a cell undergoing mitosis was seen. The existence of these mitotic figures (Fig. 5B,C) indicates that the BrdU is labeling newly born cells and not labeling cells that are undergoing DNA repair. Taken together, these results demonstrate that chronic

Figure 4. Chronic, but not acute, fluoxetine administration increases BrdU labeling in the adult hippocampus. Rats were administered fluoxetine for 1 , 5,14 , or $28 \mathrm{~d}$ and were then given BrdU for analysis of cell proliferation, as described in Figure 1. The results are the mean \pm SEM number of BrdUpositive cells in hippocampus at each time point ( $n=8$ per group). ${ }^{*} p<0.05$ significantly different from vehicle control $\left(F_{(4,35)}=4.35 ; p<0.05\right)$.

antidepressant administration increases the number of BrdUpositive cells in the adult hippocampus and that the increase in labeling can be attributed to an increase in cell proliferation.

In a separate experiment, we examined the influence of antidepressant treatment on cell proliferation when BrdU is administered without a drug washout period. Fluoxetine was administered for $14 \mathrm{~d}$ and then BrdU was administered $2 \mathrm{hr}$ after the last fluoxetine treatment. This paradigm also significantly increased the number of BrdU-positive cells (vehicle, $4962 \pm 398$; fluoxetine, $6740 \pm 498$ BrdU-labeled cells per dentate gyrus; mean \pm SEM; $n=8$ per group; $p<0.05)$. The magnitude of this increase was similar to that observed when BrdU was administered $4 \mathrm{~d}$ after the last fluoxetine treatment (Fig. 3). These results indicate that fluoxetine increases proliferation within hours after the last treatment and that this effect is sustained for at least $4 \mathrm{~d}$. Alternatively, this data provides evidence that that the increase in BrdU-labeled cells is not a rebound effect that occurs during the $4 \mathrm{~d}$ allowed for the washout period.

To determine whether the antidepressant-induced upregulation of cell proliferation is specific to the hippocampus, another brain region known to contain progenitor cells in adulthood, the subventricular zone of the lateral ventricle (Kuhn et al., 1996), was examined. Chronic ECS or fluoxetine treatment did not influence the number of BrdU-labeled cells per section of this brain region (data not shown; $p>0.05$ ). In addition to demonstrating that 

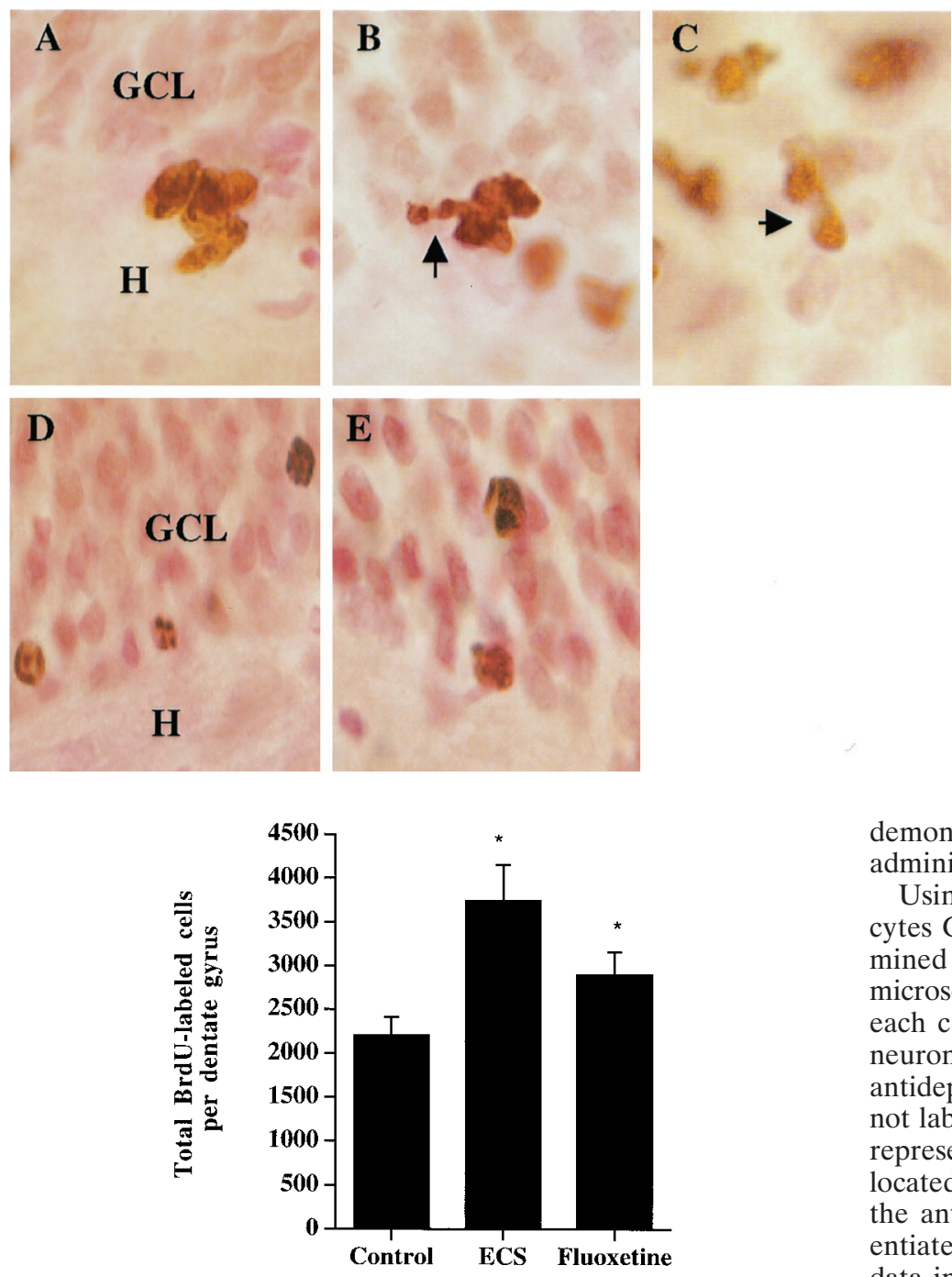

Figure 6. The number of BrdU-positive cells is increased 4 weeks after chronic antidepressant treatment. Rats received BrdU injections $4 \mathrm{~d}$ after the last ECS $(10 \mathrm{~d})$ or fluoxetine $(14 \mathrm{~d})$ treatment and were killed 4 weeks later. The results are the mean \pm SEM number of BrdU-positive cells $(n=$ 7 per group). ${ }^{*} p<0.05$ significantly different from vehicle control $\left(F_{(2,18)}=\right.$ $5.8 ; p<0.01)$.

antidepressants specifically increase cell proliferation in the hippocampus, these results also suggest that antidepressant administration does not have a general effect on the amount of BrdU entering the brain or the incorporation of BrdU into the DNA of proliferating cells.

\section{Antidepressant treatment increases neurogenesis}

Newly born cells in the hippocampus can have several fates: some cells die, whereas others survive and differentiate into mature neurons or glia. To examine the influence of antidepressant treatment on cell fate, the number and phenotype of the BrdU-positive cells was determined $28 \mathrm{~d}$ after BrdU administration, a time at which the cells have matured.

At this time the number of BrdU-positive cells was significantly increased in the animals treated with chronic ECS or fluoxetine compared with vehicle control (Fig. 6). This indicates that the proliferating cells induced by antidepressant treatment are still surviving $28 \mathrm{~d}$ later. The mature cells were found throughout the dentate gyrus, had normal granule cell morphology, and appeared ovoid or round with uniform BrdU staining throughout the nucleus (Fig. 5D,E). No clusters of mature cells were found at this time. The absolute number of BrdU-positive cells in all groups was lower relative to the $24 \mathrm{hr}$ time, in agreement with previous studies
Figure 5. Representative photomicrographs of proliferating and mature BrdU-labeled cells. $A-C$, Photomicrographs of labeled cells $2 \mathrm{hr}$ after $\mathrm{BrdU}$ injection $(1000 \times)$. At this time point proliferating cells are localized to the SGZ and often appear in clusters. The cell clusters in $A$ and $B$ contain multiple progenitor cells. Mitotic figures $(B, C$, indicated by arrow) were also evident in sections from every animal. $D, E$, Photomicrographs of labeled cells 4 weeks after BrdU injection $(1000 \times)$. At this time point mature cells are found throughout the granule cell layer and appear ovoid or round, similar to surrounding granule cells. The characteristics of the new and mature cells from control and antidepressant-treated sections were not different. Only the number of proliferating cells was significantly increased by antidepressant treatment.

demonstrating a decline in total cell number 2 weeks after BrdU administration (Gould et al., 1999a).

Using markers for mature neurons, NSE or NeuN, and astrocytes GFAP, the phenotype of the BrdU-positive cells was determined by triple immunofluorescent labeling (Fig. 7). Confocal microscopy, using z-plane sections to confirm colocalization for each cell, revealed that the majority of BrdU-positive cells were neuronal $(75 \%)$ and not glial $(13 \%)$ in both the control and antidepressant-treated groups. The remaining $12 \%$ of cells were not labeled with either a neuronal or glial marker; these cells may represent a phenotype not labeled here, or they may be cells located deeper in the tissue section and therefore not accessible to the antibodies used. They may also represent quiescent undifferentiated cells (Eriksson et al., 1998; van Praag et al., 1999b). These data indicate that the antidepressants do not affect the differentiation of cells into neurons or glia.

In a separate experiment, the influence of antidepressant treatment on the survival of cells that have already been born in the hippocampus was determined. In this experiment, we administered BrdU $1 \mathrm{~d}$ before initiating chronic fluoxetine treatment $(14 \mathrm{~d})$. Twenty-eight days after the BrdU administration (14 d after the last fluoxetine injection), there was no difference in the number of BrdU-positive cells in the hippocampus (control, $2764 \pm 320$; fluoxetine, $2808 \pm 348$ BrdU-labeled cells; mean \pm SEM; $n=6$ ). The survival rate of the newly born cells in the hippocampus is approximately the same in both the vehicle and fluoxetine-treated groups $(\sim 50 \%$ of BrdU-labeled cells in each group survives at this time point). This indicates that chronic antidepressant treatment does not directly affect the rate of maturation and survival of BrdU-positive cells in the hippocampus.

\section{DISCUSSION}

The results of this study demonstrate that chronic antidepressant administration increases neurogenesis in the dentate gyrus of the adult rat hippocampus. Upregulation of neurogenesis is observed in response to administration of different classes of antidepressants, indicating that increased neurogenesis may be a common action of antidepressant treatment. In addition, increased BrdU labeling is observed after chronic (14 or $28 \mathrm{~d}$ ), but not short-term ( 1 or $5 \mathrm{~d}$ ) antidepressant treatment. These findings indicate that the time course for the upregulation of BrdU labeling is consistent with the time delay required for the therapeutic action of antidepressants (Duman et al., 1997).

In contrast, chronic administration of the non-antidepressant 

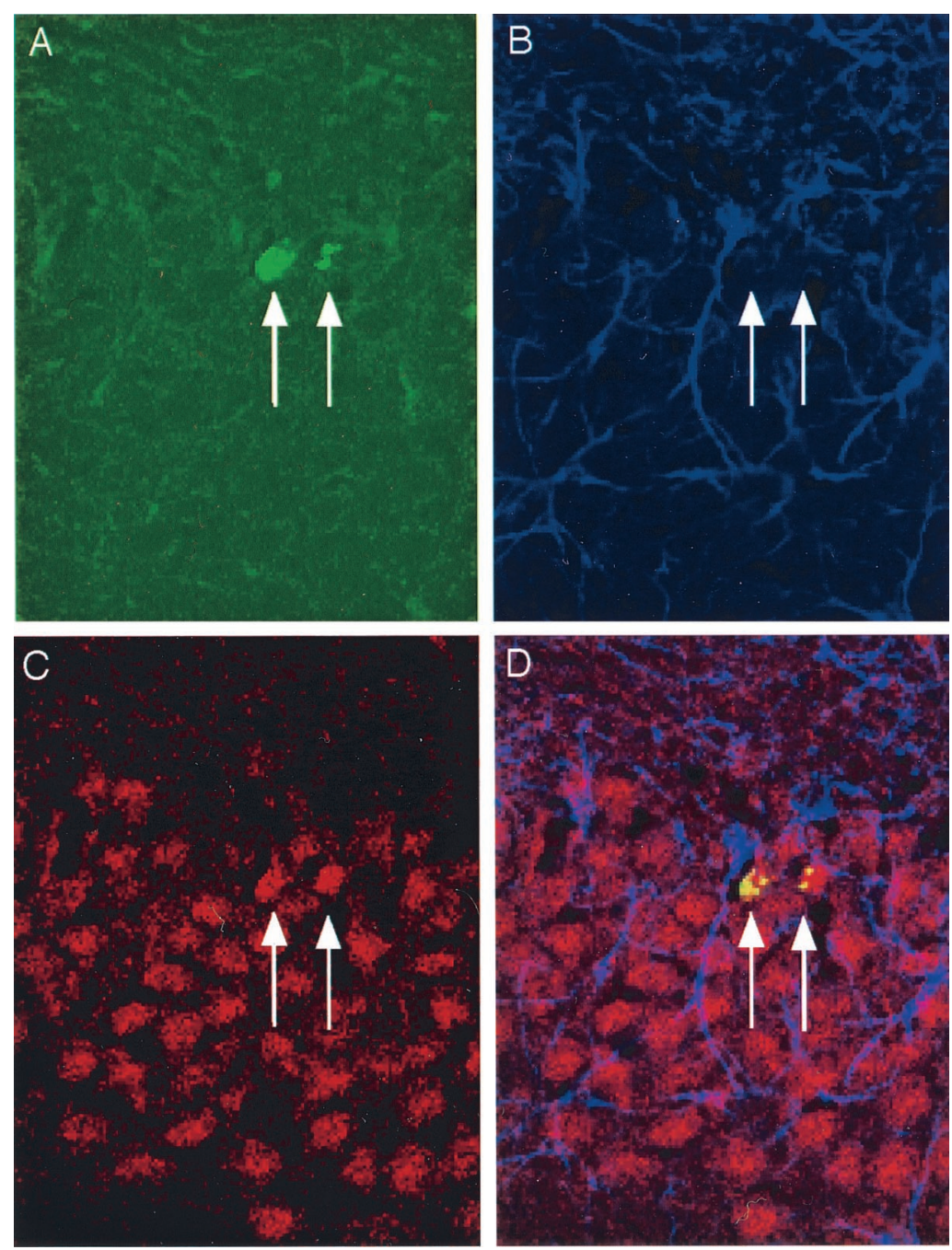

Figure 7. Triple labeling confirms that BrdU-positive cells mature into neurons. Rats received BrdU injections $4 \mathrm{~d}$ after the last ECS treatment and were killed 4 weeks later. A representative confocal laser-scanning image $(66 \times)$ of a section from a fluoxetine-treated rat that has been triple-labeled with $\operatorname{BrdU}(A$, green; BrdU-positive cells indicated by arrows), GFAP ( $B$, blue), and NeuN $(C, r e d)$. The merged image $(D)$ demonstrates cells that are double-labeled in the GCL for BrdU and NeuN but not GFAP.

psychotropic drug haloperidol, does not increase BrdU labeling in hippocampal granule cells. In addition, we have recently demonstrated that morphine, another non-antidepressant psychotropic drug, decreases BrdU labeling of granule cells (Eisch et al., 2000). These findings indicate that the upregulation of hippocampal BrdU labeling may be pharmacologically selective to the chemical antidepressant drugs. The lack of effect of haloperidol in this study differs from two previous studies, one reporting an increase (Dawirs et al., 1998), and one reporting a decrease (Backhouse et al., 1982 ) in cell proliferation. However, there are several differences between the current and these previous reports, including dose and time course of drug treatment, species and age of test animals, and the BrdU labeling protocol. One or more of these variables could account for the difference in our results. In the current study, the dose and time of haloperidol treatment were consistent with the therapeutic treatment regimen (Nibuya et al., 1995), in contrast to the two previous studies. Using this relevant treatment paradigm and the same BrdU labeling protocol that was used for the antidepressant studies, haloperidol does not increase BrdU labeling.

Regulation of neurogenesis could occur at several different stages, including cell proliferation, differentiation, and survival. We demonstrate that $2 \mathrm{hr}$ after BrdU administration, antidepressant treatment significantly increased the number of BrdU-labeled cells compared with the saline control group. This indicates that antidepressant treatment increases cell proliferation. To examine the effect of antidepressants on survival of labeled cells, BrdU was administered before the start of antidepressant treatment, and the number of labeled cells was determined 4 weeks later. Under these conditions, the survival of the BrdU-labeled cells can be determined independent of the influence of antidepressant treatment on cell proliferation. In this experiment, the number of BrdU-labeled cells in the treatment group was not different from the control group, indicating that antidepressants do not influence cell survival.

The differentiation of labeled cells was determined 4 weeks after antidepressant or saline treatment by colocalization of neuronal and glial phenotypic markers in BrdU-labeled cells. At this time point, there is a significant increase in the number of BrdU-labeled cells relative to controls. This increase is a result of the upregulation of cell proliferation by antidepressant treatment. The majority $(75 \%)$ of the surviving BrdU-positive cells express a neuronal marker (i.e., NeuN or NSE) and have physical characteristics of healthy, viable neurons. A much smaller number $(13 \%)$ of cells express a glial marker (GFAP). The remaining $12 \%$ of cells were not labeled with either cell marker and may represent another phenotype or quiescent undifferentiated cells. This ratio of labeled neurons and glia is similar to that reported in previous studies (Eriksson et al., 1998; van Praag et al., 1999b), and was not significantly influenced by antidepressant treatment. This is consistent with our finding that antidepressant treatment increases the proliferation, but not survival, of labeled hippocampal cells. Once the cells are induced to proliferate by antidepressant treatment, their survival and differentiation rates are identical to animals treated with vehicle. The result is a net increase in the number of neurons produced, or neurogenesis, in antidepressant-treated animals compared with vehicle controls.

It is not currently known whether the mature BrdU-positive neurons seen in this study are functional in vivo. However, new neurons in the granule cell layer in hippocampus have been demonstrated to send axons to the CA3 pyramidal cell layer, the 
appropriate projection area for granule cells (Markakis and Gage, 1999). Mature BrdU-labeled cells in the granule cell layer are also surrounded by synaptic vesicles, indicating that they receive synaptic inputs. Learning and memory tasks that are dependent on the hippocampus result in an upregulation of neurogenesis (Gould et al., 1999a; van Praag et al., 1999b). In addition, increased neurogenesis in response to voluntary running has recently been correlated with an increase in granule cell long-term potentiation, a cellular model of learning and memory (van Praag et al., 1999a). Taken together, these studies demonstrate that newly formed cells differentiate into mature neurons that integrate into the existing hippocampal circuitry and may increase the functional capacity of this brain structure.

The mechanisms underlying the regulation of hippocampal neurogenesis are being actively investigated. Interestingly, both the cAMP cascade and BDNF, which we have found to be upregulated by antidepressant treatment (Nibuya et al., 1995, 1996; Thome et al., 2000), have been shown to play a role in the regulation of neurogenesis. Activation of the cAMP pathway or incubation with $\mathrm{BDNF}$ is reported to increase neuronal differentiation and neurite outgrowth of progenitor cells in vitro (Palmer et al., 1997; Takahashi et al., 1998). In addition, intraventricular inf usion of BDNF is reported to increase neurogenesis in the adult olfactory bulb (Zigova et al., 1998). Yet another possibility is insulin-like growth factor (IGF-1), a growth-promoting peptide hormone that has neurotrophic properties. IGF-1 increases proliferation and survival of neurons in adult rat (Aberg et al., 2000), although antidepressant regulation of this factor has not been demonstrated. Studies are currently underway to examine the role of the cAMP response element-binding protein and BDNF, as well as other factors, in the upregulation of cell proliferation in response to antidepressant treatment.

In addition to a potential role for these second messenger and neurotrophic factor systems, preliminary studies demonstrate that direct activation of the serotonin-1A $\left(5 \mathrm{HT}_{1 \mathrm{~A}}\right)$ receptor can induce neurogenesis (Jacobs et al., 1998). This group has also demonstrated in a preliminary study that chronic fluoxetine treatment increases proliferation of granule cells (Jacobs and Fornal, 1999). Because chronic antidepressant treatment is reported to increase $5 \mathrm{HT}_{1 \mathrm{~A}}$ function (Duman, 1998; Haddjeri et al., 1998), it is possible that antidepressant treatment may increase neurogenesis in part by activation of the $5 \mathrm{HT}_{1 \mathrm{~A}}$ receptor.

Recently, two studies have demonstrated that there is a decrease in neuronal and glial density in the prefrontal cortex of postmortem brains of patients with major depression (Ongur et al., 1998; Rajkowska et al., 1999). Although the current study has centered on the hippocampus, given the recent report that neurogenesis also occurs in the adult prefrontal cortex (Gould et al., 1999b), it is possible that the effects of antidepressants on neurogenesis may extend to cortical areas as well as hippocampal regions. This possibility must be addressed in future studies.

An increase in the number and function of hippocampal granule cells could represent an important adaptive response to antidepressant agents. This effect would be in opposition to the downregulation of neurogenesis, as well as atrophy of hippocampal neurons, which occurs in response to stress. A reversal of stress-induced hippocampal neuronal atrophy has been demonstrated in animals (Watanabe et al., 1992a,b), and more recently it has been demonstrated in humans that a reversal of hippocampal atrophy occurs after treatment for Cushing's disease (Starkman et al., 1999). It is possible that antidepressant-induced upregulation of neurogenesis would oppose the reduction of hippocampal function and volume that has been reported in patients suffering from depression and other stress-related disorders (Sapolsky, 1996; Sheline et al., 1996). Future studies will be required to determine whether antidepressants increase neurogenesis in humans and to determine whether this effect is involved in the therapeutic response to these agents.

\section{REFERENCES}

Aberg MAI, Aberg ND, Hedbacker H, Oscarsson J, Eriksson PS (2000) Peripheral infusion of IGF-1 selectively induces neurogenesis in the adult rat hippocampus. J Neurosci 20:2896-2903.

Backhouse B, Barochovsky O, Malik C, Patel A, Lewis P (1982) Effect of haloperidol on cell proliferation in the early postnatal rat brain. Neuropathol Appl Neurobiol 8:109-116.

Cameron HA, Woolley CS, McEwen BS, Gould E (1993) Differentiation of newly born neurons and glia in the dentate gyrus of the adult rat. Neuroscience 56:337-344.

Dawirs RR, Hildebrandt K, Teuchert-Noodt G (1998) Adult treatment with haloperidol increases dentate granule cell proliferation in the gerbil hippocampus. J Neural Transm 105:317-327.

Duman RS (1998) Novel therapeutic approaches beyond the serotonin receptor. Biol Psychiatry 44:324-335.

Duman RS, Heninger GR, Nestler EJ (1997) A molecular and cellular theory of depression. Arch Gen Psychiatry 54:597-606.

Duman RS, Malberg J, Thome J (1999) Neural Plasticity to stress and antidepressant treatment. Biol Psychiatry 46:1181-1191.

Eisch AJ, Barrot M, Schad CA, Self DW, Nestler EJ (2000) Opiates inhibit neurogenesis in the adult rat hippocampus. Proc Natl Acad Sci USA 97:7579-7584.

Eriksson P, Perfileva E, Bjork-Eriksson T, Alborn A, Nordborg C, Peterson D, Gage F (1998) Neurogenesis in the adult human hippocampus. Nat Med 4:1313-1317.

Fuchs E, Flugge G, McEwen BS, Tanapat P, Gould E (1997) Chronic subordination stress inhibits neurogenesis and decreases the volume of the granule cell layer. Soc Neurosci Abstr 23:317.

Gould E, McEwen BS, Tanapat P, Galea LA, Fuchs E (1997) Neurogenesis in the dentate gyrus of the adult tree shrew is regulated by psychosocial stress and NMDA receptor activation. J Neurosci 17:2492-2498.

Gould E, Tanapat P, McEwen BS, Flugge G, Fuchs E (1998) Proliferation of granule cell precursors in the dentate gyrus of adult monkeys is diminished by stress. Proc Natl Acad Sci USA 95:3168-3171.

Gould E, Beylin A, Tanapat P, Reeves A, Shors TJ (1999a) Learning enhances adult neurogenesis in the hippocampal formation. Nat Neurosci $2: 260-265$.

Gould E, Reeves AJ, Graziano MSA, Gross CG (1999b) Neurogenesis in the neocortex of adult primates. Science 286:548.

Haddjeri N, Blier P, deMontigny C (1998) Long-term antidepressant treatments result in a tonic activation of forebrain 5-HT1A receptors. J Neurosci 18:10150-10156.

Jacobs B, Tanapat P, Reeves A, Gould E (1998) Serotonin stimulates the production of new hippocampal granule neurons via the $5 \mathrm{HT} 1 \mathrm{~A}$ receptor in the adult rat. Soc Neurosci Abstr 23:1992.

Jacobs BL, Fornal CA (1999) Chronic fluoxetine treatment increases hippocampal neurogenesis in rats: a novel theory of depression. Soc Neurosci Abstr 25:714.

Kempermann G, Kuhn HG, Gage FH (1997) More hippocampal neurons in adult mice living in an enriched environment. Nature 386:493-495.

Kessler RC, McGonagle KA, Zhao S, Nelson CB, Hughes M, Eshleman S, Wittchen H, Kendler KS (1994) Lifetime and 12-month prevalence of DSM-III-R psychiatric disorders in the United States: results from the national comorbidity survey. Arch Gen Psychiatry 51:8-19.

Kuhn HG, Dickinson-Anson H, Gage FH (1996) Neurogenesis in the dentate gyrus of the adult rat: age-related decrease of neuronal progenitor proliferation. J Neurosci 16:2027-2033.

Madsen TM, Treschow A, Bengzon J, Bolwig TG, Lindvall O Tingström (2000) Increased neurogenesis in a model of electroconvulsive therapy. Biol Psychiatry 47:1043-1049.

Margarinos A, McEwen B, Flugge G, Fuchs E (1996) Chronic psychosocial stress causes apical dendritic atrophy of hippocampal CA3 pyramidal neurons in subordinate tree shrews. J Neurosci 16:3534-3540.

Markakis E, Gage FH (1999) Adult-generated neurons in the dentate gyrus send axonal projections to field CA3 and are surrounded by synaptic vesicles. J Comp Neurol 406:449-460.

McEwen BS (1999) Stress and hippocampal plasticity. Annu Rev Neurosci 22:105-122.

Memberg SP, Hall AK (1995) Proliferation, differentiation and survival of rat sensory neuron precursors in vitro require specific trophic factors. Mol Cell Neurosci 6:323-325.

Nibuya M, Morinobu S, Duman RS (1995) Regulation of BDNF and trkB mRNA in rat brain by chronic electroconvulsive seizure and antidepressant drug treatments. J Neurosci 15:7539-7547.

Nibuya M, Nestler EJ, Duman RS (1996) Chronic antidepressant administration increases the expression of cAMP response element binding protein (CREB) in rat hippocampus. J Neurosci 16:2365-2372.

Ongur D, Drevets WC, Price JL (1998) Glial reduction in the subgenual prefrontal cortex in mood disorders. Proc Natl Acad Sci USA 95:13290-13295.

Palmer TD, Takahashi J, Gage FH (1997) The adult rat hippocampus contains primordial neural stem cells. Mol Cell Neurosci 8:389-404.

Parent J, Yu T, Leibowitz R, Geschwind D, Sloviter R, Lowenstein D (1997) Dentate granule cell neurogenesis is increased by seizures and contributes to aberrant network reorganization in the adult rat hippocampus. J Neurosci 17:3727-3738. 
Paxinos G, Watson C (1986) The rat brain in stereotaxic coordinates. San Diego: Academic.

Rajkowska G, Miguel-Hidalgo J, Wei J, Dilley G, Pittman S, Meltzer H, Overholser J, Roth BL, Stockmeier C (1999) Morphometric evidence for neuronal and glial prefrontal cell pathology in major depression. Biol Psychiatry 45:1085-1098.

Sapolsky R (1996) Why stress is bad for your brain. Science 273:749-750.

Sheline Y, Wany P, Gado M, Csernansky J, Vannier M (1996) Hippocampal atrophy in recurrent major depression. Proc Natl Acad Sci USA 93:3908-3913.

Starkman M, Giordani B, Gebarski S, Berent S, Schork M, Schteingart D (1999) Decrease in cortisol reverses human hippocampal atrophy following treatment of Cushing's disease. Biol Psychiatry 46:1595-1602.

Stein-Behrens B, Mattson MP, Chang I, Yeh M, Sapolsky R (1994) Stress exacerbates neuron loss and cytoskeletal pathology in the hippocampus. J Neurosci 14:5373-5380.

Takahashi J, Palmer TD, Gage FH (1998) Retinoic acid and neurotrophins collaborate to regulate neurogenesis in adult-derived neural cell cultures. J Neurobiol 38:65-81.

Takahashi T, Nowakowski RS, Caviness VS (1992) BUdR as an S-phase marker for quantitative studies of cytokinetic behaviour in the murine cerebral ventricular zone. J Neurocytol 21:185-197.

Tanapat P, Galea LA, Gould E (1998) Stress inhibits the proliferation of granule cell precursors in the developing dentate gyrus. Int J Dev Neurosci 16:235-239.
Thome J, Sakai N, Shin K-H, Steffen C, Zhang Y-J, Impey S, Storm D, Duman RS (2000) cAMP response element-mediated gene transcription is upregulated by chronic antidepressant treatment. J Neurosci 20:4030-4036.

van Praag H, Christie B, Sejnowski T, Gage F (1999a) Running enhances neurogenesis, learning, and long-term potentiation in mice. Proc Natl Acad Sci USA 96:13427-13431.

van Praag H, Kempermann G, Gage F (1999b) Running increases cell proliferation and neurogenesis in the adult mouse dentate gyrus. Nat Neurosci 2:266-270.

Watanabe Y, Gould E, Cameron H, Daniels D, McEwen B (1992a) Phenytoin prevents stress- and corticosterone-induced atrophy of CA3 pyramidal neurons. Hippocampus 2:431-435.

Watanabe Y, Gould E, Daniels DC, Cameron H, McEwen B (1992b) Tianeptine attenuates stress-induced morphological changes in the hippocampus. Eur J Pharmacol 222:157-162.

Watanabe Y, Gould E, McEwen B (1992c) Stress induces atrophy of apical dendrites of hippocampal CA3 pyramidal neurons. Brain Res 588:341-345.

West M, Slomianka L, Gundersen H (1991) Unbiased stereological estimation of the total number of neurons in the subdivision of the rat hippocampus using the optical fractionator. Anat Rec 231:482-497.

Zigova T, Pencea V, Wiegand S, Luskin M (1998) Intraventricular administration of BDNF increases the number of newly generated neurons in the adult olfactory bulb. Mol Cell Neurosci 11:234-245. 